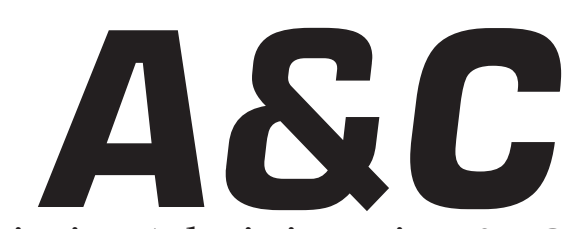

Revista de Direito Administrativo \& Constitucional

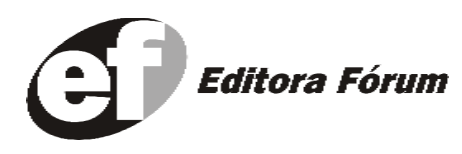

A\&C R. de Dir. Administrativo e Constitucional, Belo Horizonte, ano 4, n.15, p.1-256, jan./mar. 2004 
A\&C REVISTA DE DIREITO ADMINISTRATIVO E CONSTITUCIONAL

\section{IPDA}

Instituto Paranaense

de Direito Administrativo

Direção Geral

Romeu Felipe Bacellar Filho

Direção Editorial

Paulo Roberto Ferreira Motta

Direção Executiva

Emerson Gabardo

Conselho de Redação

Edgar Chiuratto Guimarães

Adriana da Costa Ricardo Schier

Célio Heitor Guimarães

Conselho Editorial

\begin{tabular}{|c|c|}
\hline Adilson Abreu Dallari & Manoel de Oliveira Franco Sobrinho \\
\hline Alice Gonzáles Borges & (in memoriam) \\
\hline Carlos Ari Sundfeld & Marçal Justen Filho \\
\hline Carlos Ayres Britto & Marcelo Figueiredo \\
\hline Carlos Delpiazzo & Márcio Cammarosano \\
\hline Lúcia Antunes Rocha & Maria Cristina Cesar de Oliveira \\
\hline io Bandeira de Mello & Nelson Figueiredo \\
\hline lèmerson Merlin Clève & Odilon Borges Junior \\
\hline Enrique Silva Cimma & Pascual Caiella \\
\hline Eros Roberto Grau & Paulo Eduardo Garrido Modesto \\
\hline Fabrício Motta & Paulo Henrique Blasi \\
\hline Ihermo Andrés Muñoz & Paulo Ricardo Schier \\
\hline Jorge Luís Salomoni & Pedro Paulo de Almeida Dutra \\
\hline José Carlos Abraão & Regina Maria Macedo Nery Ferrari \\
\hline ıardo Martins Cardoso & Rogério Gesta Leal \\
\hline José Luís Said & Rolando Pantoja Bauzá \\
\hline José Mario Serrate Paz & Sérgio Ferraz \\
\hline Pablo Cajarville Peruffo & Valmir Pontes Filho \\
\hline Juarez Freitas & Yara Stropa \\
\hline ulio Rodolfo Comadira & Weida Zancanner \\
\hline
\end{tabular}

Lúcia Valle Figueiredo

Luís Enrique Chase Plate

Os conceitos emitidos em trabalhos assinados são de responsabilidade de seus autores, que gozam de inteira

liberdade de opinião. e-mail para remessa de artigos, pareceres e contribuições: e.gab.@uol.com.br

ou conselho@editoraforum.com.br Endereço para envio de contribuições: Editora Fórum

Revista A\&C, Av. Afonso Pena, 2770, 15\%16 a andar, Funcionários, CEP 30130-007 - Belo Horizonte - MG

A\&C Revista de Direito Administrativo e Constitucional. Ano 3, n. 11, jan./mar. 2003. Belo Horizonte: Fórum, 2003.

Trimestral

ano 1, n.1, 1999 até ano 2, n.10, 2002 publicada pela Editora Juruá em Curitiba

ISSN: 1516-3210

1. Direito Administrativo. 2. Direito Constitucional. I. Fórum.

CDD: 342 CDU: 33.342
Editor responsável: Luis Cláudio Rodrigues Ferreira Projeto gráfico: Luis Alberto Pimenta

Diagramação: Luis Alberto Pimenta

Revisora: Olga M. A. Sousa

Pesquisa jurídica: Fátima Ribeiro - OAB/MG 74868 Bibliotecária: Nilcéia Lage de Medeiros -

CRB 1545/MG - 6 a região

(c) Editora Fórum Ltda., 2003.

Proibida a reprodução total ou parcial desta obra, por qualquer meio eletrônico, inclusive por processos xerográficos, sem autorização expressa do editor.

Distribuída em todo o território nacional

Assinaturas e comercialização:

Editora Fórum, Av. Afonso Pena, 2770, 15-16 andar, Funcionários, CEP 30130-007 - Belo Horizonte - MG Tel.: (31) 2121-4900 - 0800 704-3737

e-mail: editoraforum@editoraforum.com.br site: www.editoraforum.com.br 


\title{
Limites à Competência Regulatória dos Conselhos Profissionais
}

Ana Cláudia Finger

Advogada em Curitiba. Professora de Direito Administrativo da UniBrasil. Especialista em Direito pela PUC/PR. Mestranda em Direito do Estado pela UFPR

\begin{abstract}
Proposta de parceria entre autarquia de fiscalização profissional e sindicato representativo da classe.

Análise da Minuta de Resolução que propõe parceria entre a entidade incumbida de exercer o poder de polícia administrativa das profissões que representa e o sindicato da classe para fiscalização acerca da conduta dos profissionais em relação ao recolhimento das contribuições sindicais.
\end{abstract}

Trata-se de consulta formulada por Conselho Profissional de Fisioterapia e Terapia Ocupacional no que diz respeito a minuta de resolução que estabelece parceria entre a autarquia fiscalizadora do exercício profissional e o sindicato da classe. Segundo os termos da minuta apresentada, a parceria consiste na verificação, por parte do Conselho Regional, da conduta dos profissionais no que toca ao recolhimento das contribuições sindicais devidas ao mencionado Sindicato.

Nos termos do $\S 1^{\circ}$, do artigo $1^{\circ}$ da aludida minuta de resolução, o Conselho Regional “(...) fica impedido de expedir a Certidão de Regularidade do Profissional ou da Empresa e/ou Consultório" que não comprovar a quitação da contribuição sindical prevista no artigo 579 e 580, da Consolidação das Leis do Trabalho - CLT. Além disso, o $\S 2^{\circ}$, do mesmo dispositivo normativo, estabelece que os atos fiscalizatórios realizados por este Conselho Regional contemplarão a verificação do recolhimento de contribuição sindical.

Em primeiro lugar, imperioso se faz esclarecer que a presente manifestação não adentra no mérito da obrigatoriedade ou não do recolhimento de contribuições sindicais. A análise restringe-se quanto ao aspecto da legalidade do referido parágrafo primeiro do artigo $1^{\circ}$, bem assim a legitimidade de uma autarquia de fiscalização profissional para averiguar a situação de profissionais perante o Sindicato da classe fazendo, inclusive, o controle sobre o recolhimento de contribuições sindicais. Com efeito, infere-se que a minuta de resolução apresentada busca atrelar a expedição de certidão de regularidade de funcionamento (licença para o exercício regular da atividade) à comprovação, pelo profissional, da quitação de 
contribuição sindical devida ao respectivo sindicato.

Feita esta ressalva, cabe-me enfrentar a questão debatida.

Os Conselhos de Profissão são entidades que compõem o aparelho estatal especialmente constituídas para a preservação dos interesses da sociedade. São organismos através dos quais o Estado, de forma descentralizada, isto é, por intermédio de pessoas jurídicas especificamente criadas para esse fim, passa a intervir no exercício das profissões, condicionando e limitando tais atividades em benefício da coletividade.

Isto significa que, permitido o desempenho de uma profissão regulamentada, os Conselhos de Profissão têm poder fiscalizatório sobre essa atuação, através do estabelecimento de condicionantes para o seu regular exercício. A inobservância das regras da profissão, a prática de infração técnica ou ética, podem ensejar a aplicação de penalidades, inclusive, a cassação do registro nos casos de maior gravidade.

Trata-se, na verdade, do exercício da chamada polícia administrativa, consistente na imposição de restrições à liberdade e à propriedade impostas pelo Estado em prol do interesse coletivo. Essa prerrogativa configura verdadeiro munus indelegável, exercido no interesse maior da sociedade.

De fato, a atividade de fiscalização do exercício profissional constitui função verdadeiramente pública, decorrendo da natureza dessa função a autoridade que os agentes fiscalizadores gozam. Autoridade essa para regulamentar as profissões, estabelecendo normatização e parâmetros para o exercício profissional, e também para impor sanções.

Todavia, essa possibilidade que as entidades de fiscalização detêm para regulamentar a profissão está atrelada aos limites impostos pelo ordenamento jurídico brasileiro.

É exatamente nesse ponto que a minuta de resolução apresentada enseja algumas ponderações. Se não, vejamos:

Em determinados casos a lei já pré-determina, em termos estritamente objetivos, a situação de fato e a conduta única a ser adotada perante ela. Entretanto, tal situação, como se sabe, é rara. Isto porque ao legislador nem sempre é possível prever todas as situações de fato e regular toda a imensa gama de comportamentos humanos através de uma punctual intervenção legislativa. Vezes há, em que a generalidade e abstração da dicção legal exigem a sua explicitação.

Assim é que o ordenamento jurídico brasileiro admite a edição de atos administrativos gerais, abstratos e hierarquicamente inferiores à lei, com vistas à operacionalização da atividade administrativa. É o chamado

A \& C R. de Dir. Administrativo e Constitucional, Belo Horizonte, ano 4, n. 15, p. 183-191, jan./mar. 2004 
poder regulamentar conferido à Administração Pública.

A prerrogativa regulamentar reconhecida à autoridade administrativa é qualificada no direito brasileiro como competência específica e limitada, destinada a criar normas gerais e abstratas, desde que não introduzam novidades no ordenamento jurídico. Essa competência outorgada ao administrador público tem a finalidade única e exclusiva de estabelecer disposições operacionais uniformizadoras necessárias à fiel execução da lei cuja aplicação demande atuação da Administração Pública. ${ }^{1}$

Isto significa que, no exercício da competência regulamentar que lhe é atribuída para expedir lei material explicitando a lei formal, o administrador público haverá de ficar circunscrito aos limites da lei a ser regulamentada. E somente dentro desses limites é que será legítima, mormente porque o ordenamento jurídico brasileiro não admite os chamados regulamentos autônomos, entendidos como aqueles atos normativos que originariamente criam direitos e obrigações no mundo jurídico.

Com efeito, somente a lei pode criar ou restringir direitos - artigo $5^{\circ}$, inciso II da CF —, sendo que a competência regulamentar não poderá jamais inovar, de modo a criar, ampliar ou restringir direitos, deveres e pretensões. ${ }^{2}$ Como se vê, o dispositivo constitucional não faz referência a decreto, regulamento, portaria ou resolução, exigindo lei para que sejam impostas obrigações aos administrados em geral.

Sobre o tema, vale trazer à colação a doutrina de Celso Antônio Bandeira de Mello que, com a autoridade de sempre, leciona:

É, pois, à lei, e não ao regulamento, que compete indicar condições de aquisição ou restrição de direito. Ao regulamento só pode assistir, à vista das condições preestabelecidas, a especificação delas. (...) Deveras, disciplinar certa matéria não é conferir a outrem o poder de discipliná-la. Fora isto possível, e a segurança de que 'ninguém poderá ser obrigado a fazer ou deixar de fazer alguma coisa senão em virtude de lei', deixaria de se constituir em proteção constitucional. ${ }^{3}$

Enfim, a atribuição conferida ao administrador público para expedir atos regulamentares à lei deve, portanto, ficar circunscrita aos limites da lei,

\footnotetext{
MELLO, Celso Antônio Bandeira. Curso de Direito Administrativo. São Paulo: Malheiros, 2002, p. 316.

2 É essa a distinção entre a lei e o regulamento: a lei inova originariamente na ordem jurídica, sendo fonte primária do direito, enquanto que o regulamento, como fonte secundária, é de hierarquia inferior à lei (e, por isso, dependente dela) não podendo alterar a ordem jurídica. MELLO, Celso Antônio, op. cit., p. 305-306.

3 MELLO, Celso Antônio, id., p. 317.
}

A \& C R. de Dir. Administrativo e Constitucional, Belo Horizonte, ano 4, n. 15, p. 183-191, jan./mar. 2004 
mormente porque, como muito bem lembrado por Celso Antônio, não se trata de um poder regulamentar, mas sim "dever regulamentar", eis que é exercício de função administrativa. ${ }^{4}$ Quem exerce a função administrativa titulariza, na verdade, "deveres-poderes", ${ }^{5}$ no interesse alheio, aqui entendido o interesse público, da coletividade. Daí por que o exercício dessas prerrogativas da Administração da Pública só será legítimo quando utilizado na medida indispensável ao atendimento do interesse público.

O poder conferido ao agente público somente pode ser utilizado na média exata, como atributo do cargo ou função, não como privilégio de quem o exerce. Na função pública há a submissão total da vontade ao escopo pré-traçado na Constituição ou na lei, estando o agente público incumbido de zelar pelo interesse alheio, o da coletividade.

Mesmo nas atividades discricionárias, o agente público está circunscrito aos limites impostos pelo regime jurídico administrativo, mormente porque, como bem lembrado por Caio Tácito, a discricionariedade não é um cheque em branco. Discricionariedade — já prelecionava Adilson Abreu Dallari - "é apenas uma certa margem de liberdade para que a autoridade decida, no caso concreto, sobre a melhor forma de satisfazer o interesse público". ${ }^{6}$

A lição de Hely Lopes Meirelles não deixa margem para dúvida:

Qualquer ato da autoridade, para ser irrepreensível, deve conformar-se com a

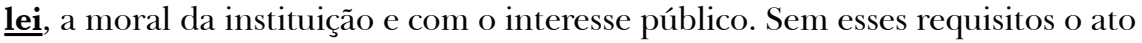
administrativo expõe-se à nulidade (...)" ${ }^{7}$ (grifos e negritos nossos)

Mais adiante, asseverou o inesquecível mestre:

O discricionarismo da Administração não vai ao ponto de encobrir arbitrariedades, caprichos, má-fé ou imoralidades administrativas. ${ }^{8}$

Se a autoridade ultrapassa as fronteiras de sua atribuição e desborda das canaletas legais ou se desvia da finalidade pública, pratica abuso de poder - ação que, entre nós, tem merecido sistemático repúdio. Tanto é que a Constituição Federal, em seu art. $5^{\circ}$, inciso LXIX, estatui expressamente

\footnotetext{
4 Na lição do administrativista quando "alguém está investido no dever de satisfazer dadas finalidades em prol do interesse de outrem, necessitando, para tanto, manejar os poderes requeridos para supri-las." O mesmo autor assinala que estes poderes são meramente instrumentais, ou seja, utilizados para o alcance da finalidade pública, sem os quais, impossível seria o desempenho das atribuições pelo agente público.

5 Celso Antônio BANDEIRA DE MELLO entende as prerrogativas da Administração Pública como deverespoderes. BANDEIRA DE MELLO, op. cit., p. 32.

DALLARI, Adilson Abreu. In: Parecer sobre a Licitação Dirigida. ILC, n. 24, p. 108/122.

MEIRELLES, Hely Lopes. Direito Administrativo Brasileiro. 13. ed. São Paulo: Revista dos Tribunais, p. 89.

8 Id., p. 91.
}

A \& C R. de Dir. Administrativo e Constitucional, Belo Horizonte, ano 4, n. 15, p. 183-191, jan./mar. 2004 
que

conceder-se-á mandado de segurança para proteger direito líquido e certo, não amparado por habeas corpus ou habeas data, quando o responsável pela ilegalidade ou abuso de poder for autoridade pública ou agente de pessoa jurídica no exercício de atribuições do Poder Público.

No que diz respeito ao exercício de um ofício ou profissão, a Constituição Federal assim estabelece:

Art. $5^{\circ}-(\ldots)$

XIII - é livre o exercício de qualquer trabalho, ofício ou profissão, atendidas as qualificações profissionais que a lei estabelecer. (grifei e negritei)

Vê-se que a liberdade de trabalho restou constitucionalmente garantida. No entanto, é sabido, essa liberdade não é ilimitada, visto que, ao estabelecê-la, o constituinte não afastou a prerrogativa legal de estabelecer pressupostos necessários para o seu exercício. Passa a prevalecer, portanto, o interesse coletivo de ser bem atendido por profissionais capacitados para o desempenho da atividade, tecnicamente habilitados em contraposição ao princípio constitucional apontado. Desta forma, cabe à lei ordinária estabelecer a regulamentação das profissões, tendo em vista as qualidades técnicas necessárias e outros requisitos que forem substancialmente convenientes.

Nestes termos, o constituinte regulamentou que a fiscalização profissional é matéria que está sujeita à reserva absoluta da lei formal. Isto significa que somente através de lei é que se estabelecerão as condicionantes e os limites para o exercício de uma profissão regulamentada.

Como entidades da Administração Pública Indireta, os órgãos de fiscalização organizam e disciplinam o exercício das profissões que representam por intermédio de resoluções, instruções e portarias, mas sempre circunscritos aos limites do poder normativo que a lei regulamentadora da profissão lhes outorga. Isto porque, na esteira do que já foi alinhavado, trata-se de atos normativos que, na pirâmide jurídica, estão alojados num patamar hierarquicamente inferior à lei, de modo que não podem inovar a ordem jurídica criando ou restringindo direitos e obrigações.

Alinhavadas tais considerações, necessárias à compreensão do tema, é de se verificar se, no caso em pauta, a resolução sob comento se encontra dentro dos limites da prerrogativa regulamentar outorgada à entidade de fiscalização profissional. Isto porque, em se tratando de um ato 
normativo hierarquicamente inferior à lei, a resolução questionada somente será considerada válida juridicamente se não extravasar os limites dispostos na lei que regula as profissões em questão.

De uma análise singela da Lei $\mathrm{n}^{\circ} 6.316 / 75$, que criou os Conselhos Federal e Regionais de Fisioterapia e Terapia Ocupacional, regulamentando o exercício dessas profissões, verifica-se que constituem requisitos para o legítimo desempenho da atividade: (i) a apresentação da carteira profissional através do registro perante o órgão competente (art. 12) e (ii) o pagamento da anuidade decorrente desse registro (art. 15).

Feita esta constatação, desde logo se infere que, ao pretender atrelar a expedição da Certidão de Regularidade de Funcionamento para os profissionais que não comprovarem a quitação da contribuição devida ao sindicato (cf. dispõe o $\S 1^{\circ}$, do artigo $1^{\circ}$ ), a Resolução em comento acaba por impor uma restrição onde a lei formal não estabeleceu e, sendo, assim, incorre em evidente extrapolamento da competência regulamentar do agente público, não podendo, destarte, ser considerada juridicamente válida.

Com efeito, da literal exegese do $\S 1^{\circ}$, do artigo $1^{\circ}$, infere-se que a Resolução apresentada estabelece uma restrição na medida em que impede o fornecimento da Certidão de Regularidade de Funcionamento, por esta autarquia, para aqueles profissionais que não comprovarem a quitação da contribuição sindical. Entretanto, em nenhum momento a Lei ${ }^{\circ}$ 6.316/75 impõe qualquer espécie de restrição ao desempenho da profissão que não a apresentação da Carteira Profissional e o recolhimento da anuidade decorrente do registro no órgão fiscalizador da profissão, vale dizer, o Conselho Regional competente.

Assim, considerando-se que somente a lei pode criar, modificar ou restringir direitos (artigo $5^{\circ}$, inciso II, da Constituição Federal), caracteriza extrapolamento dos limites da competência regulamentar a restrição contida no referido dispositivo normativo, pois, tratando-se a resolução de um expediente normativo de inferior hierarquia, não pode estabelecer restrição onde a Lei $n^{\circ}$ 6.316/75 não o faz.

Ademais disso, impende registrar que a certidão de regularidade de funcionamento, nada mais é do que uma licença para o exercício da profissão. A licença, ${ }^{9}$ como um ato administrativo vinculado assim, preenchidos os

\footnotetext{
9 A licença, assim como a autorização, são formas de exteriorização do poder de polícia, entendido como o exercício de um poder conformador da liberdade e da propriedade em prol do interesse coletivo. A distinção entre elas é que, enquanto a autorização é um ato administrativo discricionário, a licença é ato vinculado, ou sejam presentes os requisitos exigíveis, não há margem de liberdade para o administrador público concedê-la ou não.
}

A \& C R. de Dir. Administrativo e Constitucional, Belo Horizonte, ano 4, n. 15, p. 183-191, jan./mar. 2004 
pressupostos exigíveis para o ato, a sua concessão é obrigatória.

Nesse sentido, considerando-se os requisitos dispostos na Lei $\mathrm{n}^{\circ}$ $6.316 / 75$, entendo que não se revela válida a exigência contida no $\S 1^{\circ}$, do artigo $1^{\circ}$ da Resolução apresentada na sessão plenária do dia 28.01.04.

Por outro lado, necessário se faz esclarecer que tais considerações não implicam dizer que o recolhimento da contribuição sindical referida no mencionado $\S 1^{\circ}$ não seja obrigatório. Em verdade, sem embargo do evidente excesso de competência regulamentar, o que, por si só, inquina de ilegalidade a resolução em debate, entendo que este Conselho Regional não detém legitimidade para exercer o controle ali estabelecido, qual seja, averiguar e, inclusive, cercear o exercício profissional daqueles que não comprovarem o adimplemento.

Ora, a fiscalização e o controle da arrecadação das contribuições sindicais é matéria de competência exclusiva do sindicato, que certamente possui os meios e instrumentos próprios com vistas à execução de tal mister. Pretender que esse controle seja exercido pelo Conselho Regional implica, sem sombra de dúvidas, um desbordamento dos limites de sua competência fiscalizatória. Trata-se de exigência que está fora do âmbito das atribuições legalmente estabelecidas expondo, portanto, a autoridade administrativa à responsabilização por desvio de poder.

Sem embargo do apontado excesso da competência regulamentar e do evidente desvio de finalidade em que incorrerá o Conselho Regional se prevalecerem os termos da aludida resolução, não se pode perder de vista que a Constituição Federal assegura que “(...) ninguém será obrigado a filiarse ou manter-se filiado a sindicato" (art. $8^{\circ}$, inciso V), daí por que se afigura absolutamente inconstitucional o disposto no artigo 18, inciso I, do Código de Ética das profissões aqui representadas que impõe aos profissionais o dever de associar-se ou sindicalizar-se.

Ora, na medida em que a Constituição Federal em seu artigo $5^{\circ}$, inciso XX e artigo $8^{\circ}$, inciso $\mathrm{V}$, estabelece como um direito fundamental do cidadão que ninguém será obrigado a associar-se ou manter-se filiado a sindicato, é certo que a regra do Código de Ética (editado em 1978) não foi recepcionada pelo texto constitucional de 1988, sendo, à vista disso, inconstitucional tal exigência.

Outrossim, alerto que, a prevalecer os termos da Resolução apresentada, o ato administrativo que indeferir a expedição da Certidão de Regularidade de Funcionamento para os profissionais que não comprovarem o recolhi-

A \& C R. de Dir. Administrativo e Constitucional, Belo Horizonte, ano 4, n. 15, p. 183-191, jan./mar. 2004 
mento das contribuições sindicais padecerá de vício insanável.

Como manifestação da vontade da Administração Pública, o ato administrativo deve ostentar alguns requisitos que, por fundamentais, apresentam-se indispensáveis à sua validade. Um desses requisitos é a submissão incondicional ao princípio da legalidade. Esse preceito "não é um pressuposto" - como assinala Manoel de Oliveira Franco Sobrinho - "mas uma determinante essencial". ${ }^{10}$

Isto significa que o administrador público, em sua atividade, está sempre sujeito aos mandamentos da lei e deles não deve nem pode afastar-se, sob pena de praticar ato inválido e até mesmo expor-se à responsabilidade.

A legalidade é requisito essencial de qualquer ato praticado em nome da Administração Pública, e a sua observância é de cunho eminentemente obrigatório para o Administrador. É, portanto, na forma da lei, e somente desse modo, que a Administração Pública deve e pode agir. Esta assertiva constitui a essência do princípio constitucional da legalidade referido.

A ordem jurídica só se afirma quando há o pleno cumprimento das normas legais, cujo conteúdo, notadamente para a Administração Pública, é sagrado. A inobservância das normas legais, no mais das vezes, acarreta a injustiça e a truculência procedimental.

Veja-se, a título ilustrativo, que se o Poder Judiciário já exarou decisões no sentido de que o inadimplemento da anuidade decorrente do registro no próprio órgão de fiscalização profissional não pode obstar o regular desenvolvimento das atividades profissionais, que se dirá de outra contribuição cujo controle e arrecadação se inserem na esfera de competência exclusiva de outra entidade, tais como as contribuições sindicais. ${ }^{11}$

Além disso, cabe trazer à colação que o SUPREMO TRIBUNAL FEDERAL tem reiteradamente tratado desse tema, tendo seu posicionamento resultado na Súmula $\mathrm{n}^{\mathrm{o}} 70$, verbis: "É inadmissível a interdição de estabelecimento como meio coercitivo para a cobrança de tributos."

Nesse diapasão, acresce registrar que, medidas como a que é estabelecida no $\S 1^{\circ}$, do artigo $1^{\circ}$, da Resolução, constitui-se num insuportável instrumento de coação e, em sendo utilizada pela Administração Pública, caracteriza frontal violação aos ditames do princípio da moralidade,

\footnotetext{
${ }^{10}$ FRANCO SOBRINHO, Manoel de Oliveira. Curso de Direito Administrativo. São Paulo: Saraiva, p. 287.

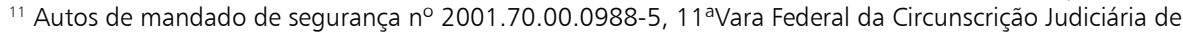
Curitiba.
}

A \& C R. de Dir. Administrativo e Constitucional, Belo Horizonte, ano 4, n. 15, p. 183-191, jan./mar. 2004 
consagrado no artigo 37, caput, da Constituição Federal.

\section{Conclusões}

Diante dos argumentos anteriormente expendidos, considerando-se que:

(i) a função primordial dos órgãos fiscalizadores de profissões é o controle ético e científico do exercício profissional (polícia administrativa em prol da sociedade);

(ii) a Lei $\mathrm{n}^{\mathrm{o}} 6.316 / 75$ não estabelece outros requisitos para o exercício das profissões que não o registro no Conselho Regional competente e o adimplemento das obrigações pecuniárias daí decorrentes;

(iii) a competência regulamentar somente será válida quando exercida nos estritos limites da lei, não podendo inovar a ordem jurídica, criando ou extinguindo direitos e obrigações;

Outrossim, registro como absolutamente salutar e de fundamental importância para o fortalecimento das profissões de fisioterapia e de terapia ocupacional na luta pela preservação da autonomia e da dignidade profissional a iniciativa de parceria entre Conselho de Fiscalização Profissional e o Sindicato respectivo, notadamente tendo em vista a legitimidade constitucional outorgada aos órgãos de representação sindical para a defesa dos interesses dos profissionais. Entretanto, tal empreendimento somente será possível e legítimo se respeitados os limites de atuação a que cada entidade está sujeita. 